\title{
Prevalence of childhood atopic diseases in the Western Province of Sri Lanka
}

\author{
N D D M Amarasekera ${ }^{1}$, N K Gunawardena ${ }^{2}$, N R de Silva ${ }^{2}$ and A Weerasinghe ${ }^{1}$ \\ (Index words: atopic diseases, allergy, asthma, rhinitis, eczema, children)
}

\begin{abstract}
Background Atopic diseases in children are major public health problems around the world and the prevalence is increasing. Our objective was to assess the prevalence of atopic diseases in schoolchildren in the Western Province of Sri Lanka.

Methods Children attending grade 5 in 17 schools in the Western Province of Sri Lanka were recruited to the study. Data were collected using the International Study of Asthma and Allergies in Childhood (ISAAC) questionnaire, which was filled by the parent/guardian of the selected children.

Results A total of 640 schoolchildren were recruited. Their mean age was 10 years (SD \pm 0.5$)$ and $55.9 \%$ of the study population was boys. Prevalence $(95 \% \mathrm{Cl})$ of asthma, rhinitis and eczema was 17\% (13.7-20.3), 21.4\% (17.8-25.1) and 5\% (3.1-7.0) respectively, while $33.7 \%$ (29.6-37.9) had one or more diseases. Only the prevalence of allergic rhinitis showed a statistically significant difference between the two sexes, being more common in boys. Less than $30 \%$ of affected children's parents recognised that their child had either asthma or rhinitis, whereas a higher number of parents (54.2\%) recognised that their child had eczema. Among children with asthma, $44.4 \%$ had rhinitis.
\end{abstract}

Conclusions The prevalence of atopic diseases in schoolchildren in grade 5 in the Western Province of Sri Lanka is as common as in other countries in the south Asian region. Parental recognition of these conditions was not satisfactory.

\section{Introduction}

Asthma, rhinitis, and eczema are common allergic diseases among children in developed countries, as well as in some developing countries [1, 2]. These diseases (also known as atopic diseases) are reported to be increasing in prevalence in some developing countries $[2,3]$. Such a rise is of concern as these chronic diseases have a major impact, not only on the physical and mental well-being of the child, but also on the socio-economic status of their families and countries [4].

The International Study of Asthma and Allergies in Childhood (ISAAC) has provided data showing a wide variation in prevalence of allergic diseases in children across the world. A simple validated questionnaire used for the ISAAC study, has provided a standard tool for epidemiological surveys of allergic diseases in children [1].

Two studies have been conducted on childhood asthma and allergies in Sri Lanka using the ISAAC questionnaire $[5,6]$. The first, conducted over ten years ago, was restricted to Gampaha, one of 25 districts in the country [5]. The second, conducted 6 years ago, was restricted to the town of Chilaw in the North-Western Province [6].

The objective of the current study was to estimate the prevalence of asthma, allergic rhinitis and eczema in a cohort of schoolchildren in the Western Province. This is the most populated of the nine provinces in the country and $28 \%$ of Sri Lanka's population of 19 million live in the Western Province. It is also the most urbanised.

\section{Methods}

This representative, cross-sectional study is part of a larger study on the association between soil-transmitted helminth infections, atopy and atopic diseases. The study population consisted of children in the fifth grade of school, attending 17 state schools in the 3 districts of the Western Province of Sri Lanka. Participating schools were selected by multi-stage stratified randomisation as follows. In the first stage, stratification was by the 4 types of schools recognised by the Ministry of Education. This categorisation is mainly based on school size. Since the smallest schools frequently draw children from the poorest communities, and the largest from the most affluent, this level of stratification takes into account the socioeconomic status of the study population. In the second stage of stratification, schools of each type were randomly selected from rural and urban areas, in proportion to the size of the urban and rural populations of the province. In the third and final stage of stratification, in each selected school, one class in Grade 5 was randomly selected as the study population. The field work was carried out between October and December 2006. ${ }^{1}$ Department of Physiology, Faculty of Medicine, University of Kelaniya, Ragama, Sri Lanka. ${ }^{2}$ Department of Parasitology,
Faculty of Medicine, University of Kelaniya, Ragama, Sri Lanka.

Correspondence: NDDMA, e-mail <manori_a@yahoo.com>. Received 18 June and revised version accepted 5 September 2009. Competing interests: none declared. 
The ISAAC questionnaire for parents was used in this study. The questionnaire had been previously translated into the local languages in accordance with the ISAAC protocol and pre-tested for use in ISAAC phase III [7]. Questionnaires were distributed to all selected children to be filled by his/her parent or guardian. Improperly filled questionnaires were sent back to the parent or the guardian with the request to complete and return the questionnaire. Students who failed to return the questionnaire were given two reminders. In accordance with ISAAC recommendations, children with reported wheezing or whistling in the chest in the last 12 months were defined as having asthma. Children who, in the last 12 months, had sneezing or a runny or blocked nose when they did not have a "cold" or the "flu" were defined as having allergic rhinitis. Children were considered to have eczema if the responses to all of the following questions were "yes": Has your child ever had an itchy rash which was coming and going for at least 6 months?; Has your child had this itchy rash at any time in the last 12 months?; Has this itchy rash at any time affected any of the following places: the folds of the elbows, behind the knees, in front of the ankles, under the buttocks, or around the neck, ears or eyes?
The parents' responses to questions were crosschecked and invalid replies were identified and excluded before entering the data. The statistical package SPSS (version 10.0) was used to analyze the data. Statistical significance was estimated with Student's t test and chi-square test. Significance was taken at $p<0.05$. Informed written consent was obtained from the respective parent or guardian. Approval for this study was granted by the Ethics and Scientific Review Committee of the Faculty of Medicine, University of Kelaniya.

\section{Results}

We studied a total of 640 children and 55.9\% were boys. The mean age was 10 (SD 0.5) years. The demographic characteristics of the study population are shown in Table 1. Five hundred and eleven (79.8\%) returned the completed questionnaire. The prevalence rates for asthma, allergic rhinitis and eczema are shown in Table 2. There were no statistically significant sex-related differences, except for rhinitis, which was commoner in boys than in girls. Among children who had evidence of allergic diseases, the majority $(118 / 169,70 \%)$ had only one disease and very few (2) children had all three allergic diseases.

Table 1. Characteristics of the study population $(n=640)$

\begin{tabular}{|c|c|}
\hline Characteristic & Number (\%) \\
\hline \multicolumn{2}{|l|}{ Sex } \\
\hline Male & $358(55.9)$ \\
\hline Female & $282(44.1)$ \\
\hline \multicolumn{2}{|l|}{ District } \\
\hline Colombo & $244(38.1)$ \\
\hline Gampaha & $221(34.5)$ \\
\hline Kalutara & $175(27.3)$ \\
\hline \multicolumn{2}{|c|}{ Returned the completed questionnaire } \\
\hline Boys & $277(77.4)$ \\
\hline Girls & $234(83.0)$ \\
\hline Total & $511(79.8)$ \\
\hline \multicolumn{2}{|c|}{ Educational level of the chief occupant of the house* } \\
\hline No formal education & $22(4.5)$ \\
\hline Primary school ${ }^{\text {a }}$ & $27(5.5)$ \\
\hline Secondary school b & $425(87.3)$ \\
\hline Higher education ${ }^{c}$ & $13(2.7)$ \\
\hline
\end{tabular}

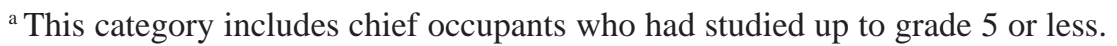

${ }^{\mathrm{b}}$ This category includes chief occupants who had studied beyond grade 5 but not had higher education.

c This category includes chief occupants who had completed formal schooling and had obtained a higher educational qualification (e.g., diploma, degree etc.).

*Percentages are based on the number of responders 


\section{Table 2. Prevalence of asthma, allergic rhinitis and eczema in the study population}

\begin{tabular}{lcccc}
\hline & \multicolumn{5}{c}{ Number positive (\%, 95\% CI) } \\
& Overall $(n=511)$ & Boys $(n=277)$ & Girls $(n=234)$ & $p$ value* \\
\hline Asthma & 85 & 49 & 36 & 0.524 \\
Rhinitis & $(17.0,13.7-20.3)$ & $(18.0,13.4-22.6)$ & $(15.9,11.1-20.6)$ & 0.021 \\
Eczema & 104 & 67 & 37 & 0.948 \\
& $(21.4,17.8-25.1)$ & $(25.4,20.1-30.6)$ & $(16.7,11.8-21.7)$ & 11 \\
One or more disease & 24 & 13 & $(5.1,2.2-8.0)$ & 0.069 \\
\hline
\end{tabular}

\footnotetext{
* Chi square test

CI - Confidence Interval
}

Among 85 children who had asthma, 21 (24.7\%) had 4 or more attacks in the last 12 months, while the sleep of 11 (12.9\%) was disturbed on one or more nights per week due to wheezing. Wheezing was severe enough to limit their speech in 15 (17.6\%) children. Exercise induced wheezing, rhinitis, eczema, and either rhinitis or eczema was observed in 43 (50.6\%), 36 (42.4\%), 4 (4.7\%), and 38 (44.7\%) asthmatic children respectively.

Approximately half (49\%) of the 104 children with rhinitis had accompanying conjunctivitis. Rhinitis was severe enough to interfere extensively with daily activities in 5 (4.8\%) children. August (33/104) and September (31/104) were reported as the most common periods for the exacerbations of rhinitis symptoms. None of the children with eczema complained that their symptoms were severe enough to keep them awake on more than one night per week.

In response to the direct question "Has your child had asthma?”, only $22.4 \%$ of those whose children had symptoms of asthma gave a positive answer, while $29.8 \%$ and $54.2 \%$ gave positive answers to direct questions on rhinitis and eczema respectively.

\section{Discussion}

The prevalence of atopic diseases in a representative sample of children studying in grade 5 in schools in the Western Province was 33.7\%. Rhinitis was the most common disease (21.4\%) followed by asthma (17\%) and eczema (5\%). Our results concur with those from a study carried out in 2003 on schoolchildren in Chilaw district of Sri Lanka which found that $22 \%$ had allergic rhinitis and $17 \%$ had asthma [6]. According to the ISAAC study, the highest prevalence of asthma has been reported from
United Kingdom, Australia, New Zealand and some parts of America with a range of $20 \%-37.6 \%$ [2], which is much higher than that observed in our study. The Sri Lankan rates are however, much higher than those reported from other countries in the region; India 6.4\%, Pakistan 11.7\%, Indonesia 5.2\% [2].

A prevalence of more than $30 \%$ has been reported for allergic rhinitis in African and Latin American countries. We found that the prevalence of allergic rhinitis was higher than that reported from the countries in the region: India $10 \%$, Pakistan $16.8 \%$, Indonesia 4.8\% [2]. With respect to eczema, Sri Lanka appears to have a similar prevalence to India $(3.7 \%)$ but much lower than that of Pakistan (13.2\%) [2].

In our study, boys were found to have a higher frequency of rhinitis compared to girls, which is different to that reported by Fernando et al., who did not observe a significant gender difference for rhinitis [6]. Karunasekera et al. [5] reported that they could not observe a significant difference for asthma between girls and boys, which is similar to our observation, while Fernando et al. [6] reported a higher prevalence in boys. Overall, a male preponderance in allergic diseases has been observed worldwide [8-11].

Among children who had evidence of any atopic disease, $70 \%$ had only one disease, similar to the rate of $72.9 \%$ observed in the ISAAC study in many countries [1]. Nearly $7 \%$ of children had both asthma and rhinitis. The presence of allergic rhinitis in a significant proportion of asthmatic children (44.4\% in this study) is an almost universal finding, strengthening the concept of 'united airway disease' [12].

A study carried out in 1998, on schoolchildren of 5-11 years in the Gampaha district, found that 23\% had asthma, 10\% had allergic rhinitis and 3\% had eczema [5]. 
Comparison of this data with ours suggests that a substantial increase has occurred in the prevalence of allergic rhinitis among children, whereas the prevalence of asthma has declined or remained unchanged. This trend, where the prevalence of asthma has decreased or remained unchanged in spite of increased prevalence of allergic rhinitis, has been observed among children in many parts of the world [2,13], specially, in the Asia-Pacific region [14-16]. Scientists have had difficulty in finding an acceptable explanation for this observation.

Although a definite classification with regard to the severity of the disease cannot be explored from the ISAAC questionnaire, the influence of rhinitis symptoms on daily activities of the child gives some indication to the severity of the disease. Based on this, a considerable number of children in our study have moderate - severe rhinitis (20.2\% of children with rhinitis).

An interesting aspect of the clinical features of children with rhinitis in this study was that symptoms became worse during the period of August and September. Patients with allergic rhinitis experience worsening of symptoms in pollen seasons in temperate countries [17, 18]. Since Sri Lanka is a tropical country with no clear demarcation of seasons, this cannot be directly attributed to a seasonal change. In the Western Province, where the study was carried out, August and September are relatively dry months in which, heavy winds blowing during these months could spray pollens into the environment, aggravating symptoms in children who are already sensitized to pollens. Further research is needed to support this hypothesis.

\section{References}

1. ISAAC Steering Committee. Worldwide variation in prevalence of symptoms of asthma, allergic rhinoconjunctivitis, and atopic eczema: ISAAC. The International Study of Asthma and Allergies in Childhood. Lancet 1998; 351: 1225-32.

2. Asher MI, Montefort S, Bjorksten B, et al. Worldwide time trends in the prevalence of symptoms of asthma, allergic rhinoconjunctivitis, and eczema in childhood: ISAAC Phases One and Three repeat multicountry cross-sectional surveys. Lancet 2006; 368: 733-43.

3. Teeratakulpisarn J, Pairojkul S, Heng S. Survey of the prevalence of asthma, allergic rhinitis and eczema in schoolchildren from Khon Kaen, Northeast Thailand, an ISAAC study. International Study of Asthma and Allergies in Childhood. Asian Pacific Journal of Allergy and Immunology 2000; 8: 187-94.

4. Weber RW. Allergic rhinitis. Primary Care 2008; 5: 1-10.
5. Karunasekera KAW, Perera KPJ, Perera MTPR, Abenarayana J. Prevalence of asthma and atopic symptoms in children aged 5-11 years. Sri Lanka Journal of Child Health 2003; 32: 11-4.

6. Fernando MAM, Senathilake PHRS, Perera BJC. Body mass index, allergic rhinitis and asthma in children. Sri Lanka Journal of Child Health 2004; 33: 102-5.

7. Wickremasinghe AR, Gunasekera K. International study of asthma and allergies in childhood (ISAAC study). In: Proceedings of the Symposium on Respiratory Diseases, Colombo 2004. Respiratory Disease Study Group, Sri Lanka.

8. Behbehani NA, Abal A, Syabbalo NC, et al. Prevalence of asthma, allergic rhinitis, and eczema in 13-14 year old children in Kuwait: an ISAAC study. International Study of Asthma and Allergies in Childhood. Annals of Allergy, Asthma and Immunology 2000; 85: 58-63.

9. Janahi IA, Bener A, Bush A. Prevalence of asthma among Qatari schoolchildren: International Study of Asthma and Allergies in Childhood, Qatar. Pediatric Pulmonology 2006; 41: 80-6.

10. Anthracopoulos MB, Antonogeorgos G, Liolios E, et al. Increase in chronic or recurrent rhinitis, rhinoconjunctivitis and eczema among schoolchildren in Greece: three surveys during 1991-2003. Pediatric Allergy and Immunology 2009; 20: $180-6$.

11. Rahimi Rad MH, Hejazi ME, Behrouzian R. Asthma and other allergic diseases in 13-14 year-old schoolchildren in Urmia: an ISAAC study. Eastern Mediterranean Health Journal 2007; 13: 1005-16.

12. Bousquet J, Van Cauwenberge P, Khaltaev N. Aria Workshop Group; World Health Organization. Allergic rhinitis and its impact on asthma. Journal of Allergy and Clinical Immunology 2001; 108 (Sup): S147-334.

13. von Mutius. The rising trends in asthma and allergic disease. Clinical and Experimental Allergy 1998; 28 (Sup): 45-9.

14. Lee SL, Wong W, Lau YL. Increasing prevalence of allergic rhinitis but not asthma among children in Hong Kong from 1995 to 2001(Phase 3 International Study of Asthma and Allergies in Childhood. Pediatric Allergy and Immunology 2004 ; 15: 72-8.

15. Lee YL, Hwang BF, Lin YC, Guo YL Taiwan ISAAC study group. Time trends of asthma prevalence among schoolchildren in Taiwan: ISAAC phase I and III surveys. Paediatric Allergy and Immunology 2007; 18: 188-95.

16. Wong GW, Leung TF, Ko FW, et al. Declining asthma prevalence in Hong Kong Chinese schoolchildren. Clinical and Experimental Allergy 2004; 34: 1550-5.

17. Ross AM, Fleming DM. Incidence of allergic rhinitis in general practice, 1981-92. British Medical Journal 1994; 308: 897-900.

18. Parikh A, Scadding GK. Fortnightly review: Seasonal allergic rhinitis. British Medical Journal 1997; 314: 1392-5. 